\title{
Buffy Coat Preparation
}

National Cancer Institute

\section{Source}

National Cancer Institute. Buffy Coat Preparation. NCI Thesaurus. Code C72895.

A process using centrifugation of whole blood to obtain a white blood cell layer highly enriched for neutrophils, lymphocytes, monocytes and progenitor cells. 